\title{
Çocukluk Çağında Vajinal Reflü: İki Olgu Sunumu
}

\author{
Vaginal Reflux in Childhood: Two Case Reports
}

\author{
Ahmet Midhat ELMACI ${ }^{1}$, Metin GÜNDÜZ ${ }^{1}$, Hayrullah ALP ${ }^{2}$ \\ 1. Dr. Ali Kemal Belviranlı Kadın Doğum ve Çocuk Hastalıkları Hastanesi, Çocuk Nefrolojisi, Konya, Türkiye \\ 2. Selçuk Üniversitesi Tıp Fakültesi, Çocuk Cerrahisi, Konya, Türkiye \\ 3. Dr. Ali Kemal Belviranlı Kadın Doğum ve Çocuk Hastalıkları Hastanesi, Çocuk Kardiyolojisi, Konya, Türkiye
}

\section{ÖZET}

Vajinal reflü, miksiyon strasinda idrarın geri akım ile vajen içerisine doğru birikimidir. Bu durum genellikle prepubertal kızlarda görülen ve yapısal anormalliğin olmadiğı fonksiyonel bir işeme bozukluğudur. Asemptomatik bakteriüriden tekrarlayan idrar yolu enfeksiyonu ve gündüz idrar kaçırmaya kadar değişik bulgularla ortaya çıkabilir. Bu yazıda idrar yolu enfeksiyonu öyküsü ve gündüz idrar kaçırma sikayeti ile bassvuran ve vajinal reflü saptanan iki olgu sunulmuştur. Illk hasta 9 yaşındayd ve tekrarlayan idrar yolu enfeksiyonu nedeniyle istenen işeme sistoüretrogramda, işemenin erken fazında vajinaya doğru geri dolum tespit edildi. On yaşındaki ikinci hasta idrar kaçırma şikayetiyle başvurdu ve üriner sistem ultrasonografisinde vajende, miksiyon sonrast kaybolan sivı birikimi tespit edildi. Her iki hastaya da tuvalet eğitimi verildi ve takiplerinde şikayetleri kayboldu.

Anahtar Kelimeler: vajinal reflü, alt üriner sistem disfonksiyonu, çocuk

\section{ABSTRACT}

Vaginal reflux is defined as reflux of urine back into the vaginal vault during voiding. This condition is a type of lower urinary tract dysfunction commonly seen in prepubertal girls without structural abnormalities. The clinical presentation is diverse, varying from asymptomatic bacteriuria to recurrent urinary tract infections, and urinary incontinence. In this case report, we present two cases of vaginal reflux presented with urinary tract infection and urinary incontinence. The first patient was a 9-year-old girl with a complaint of recurrent urinary tract infection. Voiding cystourethrogram demonstrated retrograde filling of the vagina during early voiding phase. The second patient was 10 years old who had urinary incontinance and urinary tract ultrasonography revealed a collection of the vagina that disappeared after voiding. The patients were managed with toilet training, and remained free of symptoms afterwards.

Keywords: vaginal reflux, lower urinary tract dysfunction, child

\section{İletişim}

Sorumlu Yazar: Dr. Ahmet Midhat ELMACI

Adres: Dr. Ali Kemal Belviranlı Kadın Doğum ve Çocuk Hastalıkları Hastanesi, Çocuk Nefroloji Kliniği, Fatih Mahalle, Yeni İstanbul Cadde No: 30, 42285, Selçuklu, Konya, Türkiye

Tel:+90(332) 2354205 Gsm:+90(505) 8987545 Fax:+90(332) 2376025

E-Posta: drmidhat@hotmail.com

Makale Geliș: 03.08.2018

Makale Kabul: 03.12.2018

DOI: http://dx.doi.org/10.16948/zktipb.450696

\section{GİRIŞ}

Alt üriner sistem disfonksiyonu, anatomik veya nörolojik açıdan normal olan çocuklarda, tekrarlayan idrar yolu enfeksiyonu (IYYE) ve idrar inkontinansının en önemli sebeplerinden birisidir. İşeme bozukluklarının çocukluk çağındaki gerçek s1klığ 1 tam bilinmemekle birlikte epidemiyolojik çalışmalarda, okul çağındaki çocuklarda \%20 oranında görüldüğ̈̈ bildirilmiştir. Pediatrik üroloji polikliniğine başvuranların \%30-40'inı da bu hasta grubu oluşturmaktadır (1). Çocuklarda alt üriner sistem disfonksiyonu başlığ 1 altında aşırı aktif mesane, disfonksiyonel işeme, işemeyi erteleme ve giggle (kıkırdama) inkontinansı bulunmaktadır. $\mathrm{Bu}$ bozukluklar gündüz idrar kaçırma şeklinde ortaya çıkabilir (2).

Vajinal reflü (VR) prepubertal kız çocuklarında görülen, işeme esnasında idrarın vajina içerisinde birikmesi ile karakterizedir. Yapılan bir çalışmada gündüz idrar inkontinansı olan kız çocuklarında VR sıklığ $1 \% 12$ bulunmuştur (3).

Bu yazıda tekrarlayan IYYE öyküsü ve gündüz idrar kaçırma nedeniyle müracaat eden ve VR tanısı konulan iki olgu sunulmuştur.

\section{OLGU - 1}

Dokuz yaşında kız hasta gündüz idrar kaçırma şikayetiyle müracaat etti. Özgeçmiş sorgusunda son iki yılda yaklaşı 7-8 kez İYE tanısı aldığ 1 ve bunlardan bir tanesini ateşli geçirdiği öğrenildi. Uykuda idrar kaçırma, sık işeme, acil işeme isteği, enkoprezis ve kabızlık şikayeti yoktu. Fizik incelemede vücut ağırllğ $127.5 \mathrm{~kg}(25-50 \mathrm{p})$, boy $136 \mathrm{~cm}(75 \mathrm{p})$, kan basinc1 90/60 mmHg olarak bulundu. Sistemik muayenede özellik yoktu, genital muayenesinde üretral anomali saptanmadi. Idrar analizi, idrar kültürü ve üriner ultrasonografi (US) normal olarak değerlendirildi. Statik böbrek sintigrafisinde (Tc-99m Dimerkaptosüksinik asit) sağ böbrek normaldi, sol böbrekte radyoaktivite dağılımı heterojendi ancak kortikal defekt saptanmadi. İșeme sistoüretrograminda (ISUG) mesane hacmi ve konturları normaldi, reflü saptanmadı, vajene kontrast madde geçişi izlendi (Resim 1, 2). Hastaya bacaklarını açarak ve klozete ters oturarak işeme önerildi. Üç aylık takibinde semptomlarında belirgin düzelme gözlendi ve IYE saptanmadi. 


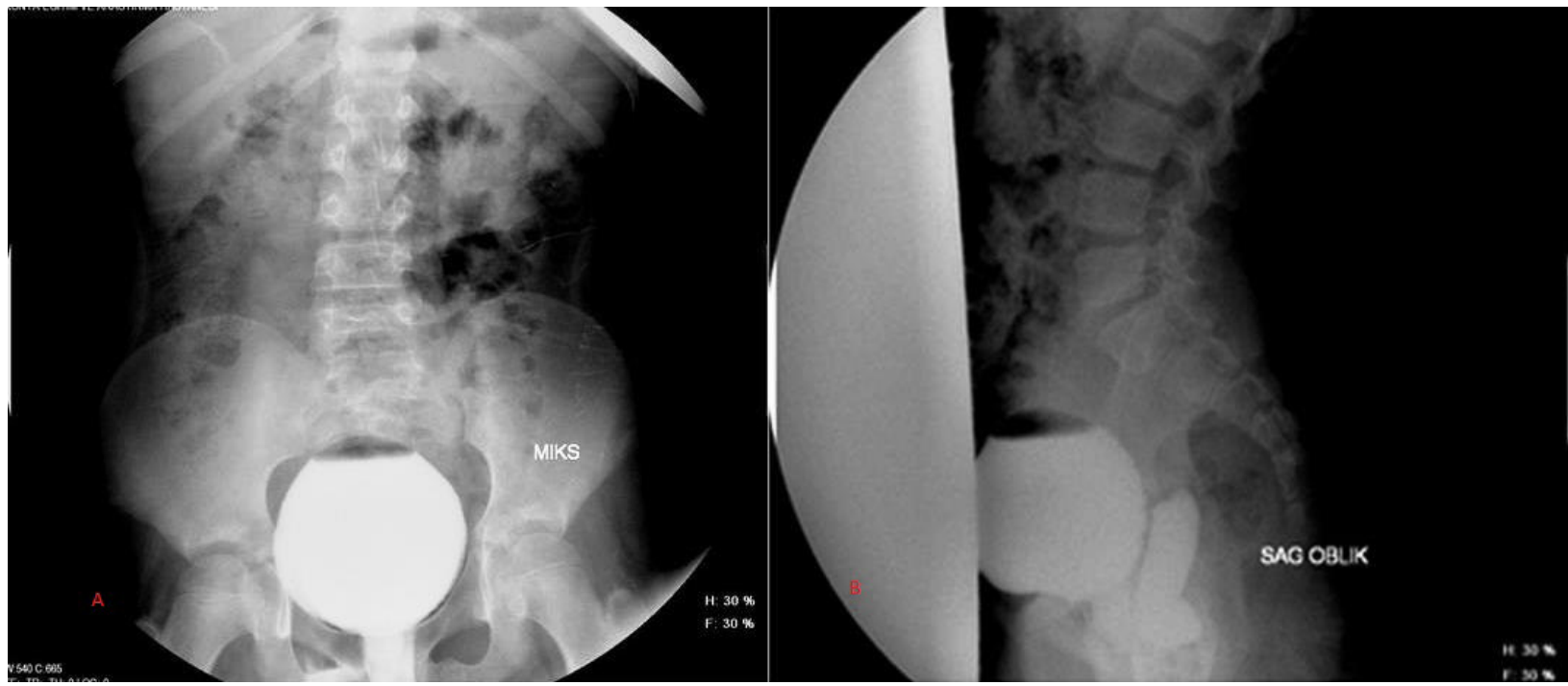

Resim 1: Olgu 1'in işeme sistoüretrogramında vezikoüreteral reflü gözlenmedi (A), işemenin erken fazında vajene kontrast madde dolumu (B).

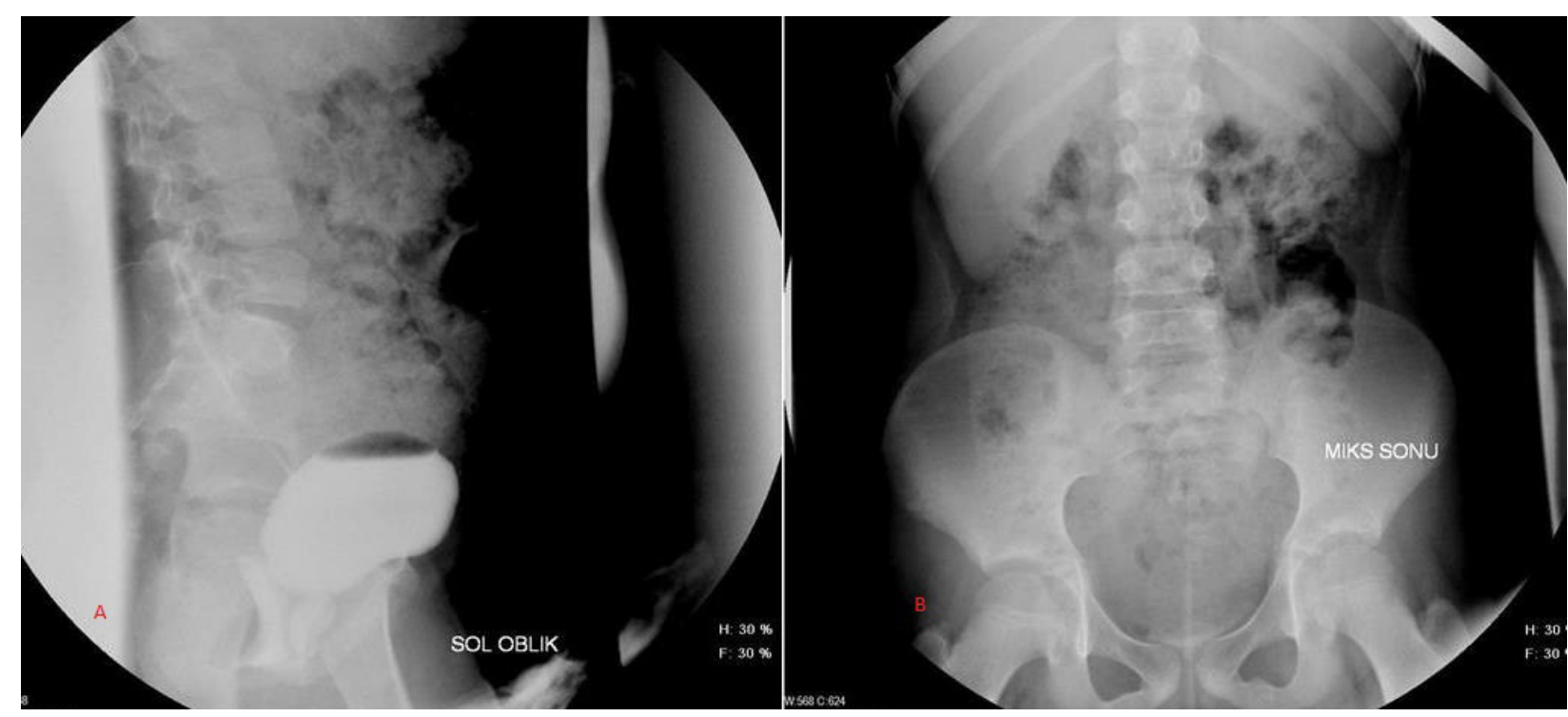

Resim 2: Olgu 1'in ișeme sistoüretrogramında işemenin geç fazında vajendeki birikimin azalması (A), ișeme sonrası birikimin tamamen kaybol$\operatorname{mas} 1(\mathrm{~B})$.

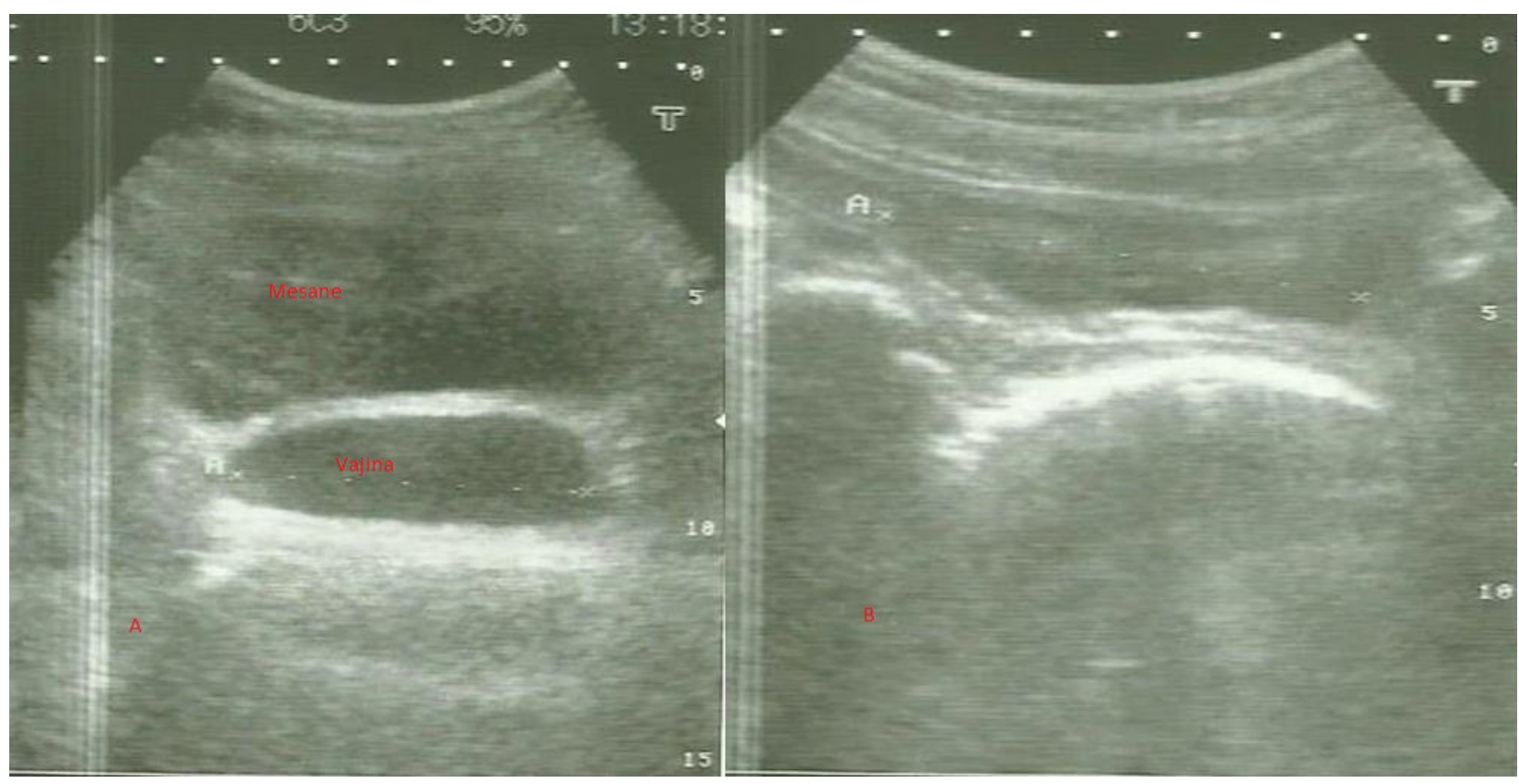

Resim 3: Olgu 2'nin üriner ultrasonografisinde vajendeki sıvı birikimi (A), işeme sonrasında birikimin kaybolması (B). 


\section{OLGU - 2}

On yaşında kız hasta gündüz damlama şeklinde idrar kaçırma ve vajinal akıntı şikayetiyle müracaat etti. Özgeçmiş sorgulamada bir kez ateşsiz IYE öyküsü mevcuttu. Uykuda idrar kaçırma, sı1k işeme, acil işeme isteği, enkoprezis ve kabılılı şikayeti yoktu. Fizik incelemede vücut ağırlığ 29 kg (25 p), boy $140 \mathrm{~cm}$ (50-75 p), kan basinc1 100/60 mmHg olarak bulundu. Sistemik muayenede özellik yoktu, genital muayenesinde üretral anomali saptanmadi. İrar analizi ve idrar kültürü normal olarak değerlendirildi. Üriner US' de sol böbrek 89 mm, sağ böbrek $84 \mathrm{~mm}$, mesane kapasitesi $423 \mathrm{cc}$, mesane cidar kalınlığı $1.3 \mathrm{~mm}$ bulundu. Mesane inferiorunda, orta hatta cidarı $2.7 \mathrm{~mm}$ kalınlıkta ve yaklaşık $40 \mathrm{cc}$ hacimde anekoik kistik görünüm izlendi ve işeme sonrası bu yapının kaybolduğu saptandı (Resim 3). Hastada mevcut bulgularla VR düşünülerek işeme eğitimi verildi. Hastanın 2 aylık takibinde semptomları tamamen düzeldi.

\section{TARTIŞMA}

Vajinal reflü, alt üriner sistem disfonksiyonuna sebep olup işeme sırasında idrarın geri akım ile vajen içinde birikimi ile karakterize bir durumdur. İşeme sonrasında vajende biriken idrarın yerçekimi etkisiyle sızıntı şeklinde damlaması, idrar kaçırmanın sebebini oluşturmaktadır (2). Alt üriner sistem disfonksiyonu çocukluk çağında sık karşılaşılan bir problemdir ve genellikle tekrarlayan IYE ile ilişkilidir (1). İlk olguda tekrarlayan IYYE ve ikinci olguda ise bir kez IYE öyküsü mevcuttu.

Çocuklarda alt üriner sistem disfonksiyonu genelde davranışsal sebeplere bağlıdır. Özellikle işeme esnasında, bacakların kapalı tutulması veya çaprazlanması önemli risk faktörlerindendir (2). Çocuklarda obezite, labial yapışıklık ve üretral mea anomalileri diğer risk faktörleridir (4). Her iki olgumuzun vücut ağırlığı normaldi, genital muayenelerinde labial yapışıklık veya meatal anomali tespit edilmedi.

Vajinal reflünün tanısında US, basit ve non-invaziv bir yöntemdir. Ancak çocukluk yaş grubunda inceleme için yeterli mesane hacmi her zaman mümkün olmayabilir. Ayrıca US ile miksiyon öncesi koleksiyonu görüp miksiyon sonrası kaybolduğunu tespit etmek de inceleyen kişinin deneyimine bağlıdır (5). Ateşli IYYE geçiren hastalarda sıklıkla kullanılan ISUG, işeme sırasında kontrast maddenin vajende birikimini doğrudan gösterebilir. Tanının konulamaması durumunda alternatif görüntüleme yöntemleri olan MR veya BT ürografi kullanılabilir (4). İlk olguda bu sebeple tekrarlayan IYE öyküsünden dolayı öncelikle VUR araştırılmış ve ISUG planlanmıştır.

Vajinal reflünün tedavisi tuvalet eğitiminin yeniden düzenlenmesidir. Klozete ters oturma, bacakların açılarak miksiyon yapması önerilir (1). Her iki olgumuza işeme eğitimi verildi ve takibinde şikayetlerinde belirgin düzelme gözlendi.
Sonuç olarak VR, çocukluk çağında tekrarlayan IYE ve inkontinansa sebep olabilir. Özellikle prepubertal kız çocuklarında IYE ve gündüz idrar inkontinansı birlikteliğinde, VR ayırıcı tanıda düşünülmelidir.

\section{$K A Y N A K L A R$}

1. Ballek NK, McKenna PH. Lower urinary tract dysfunction in childhood. Urol Clin N Am 2010;37:215-28.

2. Austin PF, Bauer SB, Bower W, Chase J, Franco I, Hoebeke $P$, et al. The standardization of terminology of lower urinary tract function in children and adolescents: Update report from the standardization committee of the International Children's Continence Society. Neurourol Urodyn 2016;35:471-81.

3. Mattsson $S$, Gladh G. Urethrovaginal reflux--a common cause of daytime incontinence in girls. Pediatrics 2003;111:1369.

4. Balani A, Alwala S, Kumar DA, Karnawat A, Marda SS, Zanke RB. Nonobstructive hydrocolpos due to vesicovaginal reflux: expanding the differential diagnosis. Jpn $J \quad R$ a d $i$ o $l$ 2015;33:287-90.

5. Kilicoglu G, Aslan AR, Oztürk M, Karaman IM, Simsek MM. Vesicovaginal reflux: recognition and diagnosis using ultrasound. Pediatr Radiol 2010;40:114-7. 